\title{
Integrated Versus Traditional Method in Basic Medical Science Education: A Comparative Study from an Indian Medical College
}

\author{
Rishi Pokhrel', Aseem Tandon', Rajan Bhatnagar ${ }^{3}$
}

${ }^{1}$ Nepalese Army Institute of Health Sciences, Kathmandu, Nepal. ${ }^{2}$ Armed Forces Medical College, India. ${ }^{3}$ Department of Anatomy, Andaman and Nicobar Islands Institute of Medical Sciences, Port Blair, India.

\section{ABSTRACT}

Introduction: Medical education is at crossroads with various approaches in use throughout the world. Many medical schools in developing countries are on the verge of transition from traditional didactic lecture based approach to a problem-based approach. This study was conducted to evaluate the efficiency and efficacy of horizontal integration in comparison to isolated didactic lectures. Methods: This study was conducted at an Indian Medical college where integration is not routinely practiced. Lectures of anatomy and physiology were integrated and students' understanding was assessed using pre-test and post-test in the form of 10 multiple-choice questions each. Opinion of students was taken using a questionnaire. Results: Total students participating in the study were 118. The mean score in pretest was found to be $5.32 \pm 1.88$ and mean post-test score was $5.43 \pm 1.89$. Students $t$ test revealed a $P$ value of 0.65 reflecting no statistically significant difference in the results. In the subjective assessment $76 \%$ of students didn't have any past experience of integration of 2 different subjects, $87 \%$ students said that integration of anatomy and physiology lectures facilitated the understanding of the subject, $75 \%$ students wanted more topics to be taught in an integrated manner in future whereas $23 \%$ students say that only few relevant topics should be integrated. $47 \%$ of students recommended the integration of more subjects and the subject chosen was biochemistry. Most students said that such integration provided a better and holistic understanding of topics being covered. Students identified no disadvantages of integration. Conclusion: The objective result showed no significant improvements in scores. On the other hand the subjective response of the students pointed towards an integrated approach being superior to stand alone didactic lectures in providing better understanding.

Keywords: medical education; integration; problem based learning

\section{INTRODUCTION}

Anatomy has always been a cornerstone of medical education disregard of nation or specialty. Dissection and didactic lectures were its only methods of teaching in the past. A multiple range of special study modules like

integration, problem based approach and community based approach is now replacing

Correspondence: Rishi Pokhrel, Nepalese Army Institute of Health Sciences,

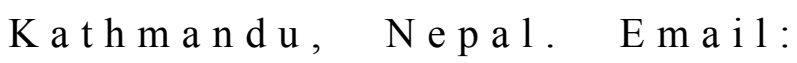
rongon28us@yahoo.com 
the traditional teaching methodology ${ }^{1}$. Anatomy curriculum is undergoing international reform but current framework lacks uniformity among institutions ${ }^{2}$.

Many medical institutions in the western world and some even in developing countries have now adopted integrated and problem based learning (PBL) approaches. Medical council of India (MCI) and Maharashtra University of health sciences (MUHS), to which our college is affiliated, still advocate the traditional teaching methods with suggestion of integration of related and most essential subjects.

Integration is a concept that espouses the curriculum as an educational program where the whole is greater than the sum of the parts ${ }^{3}$. Horizontal and vertical integration is definitely the initial step towards the PBL approach. In spite of its wide popularity, the transitions from traditional didactic lectures to PBL are still debatable.

Current literature is found to be divided on the efficacy and efficiency of integration and PBL with no unanimous evidence in support of integrated approach or PBL. The aim of the study was to compare the two methods i.e. isolated didactic lectures and horizontally integrated lectures and assess the effectiveness of such integration.

\section{METHODS}

This study was undertaken with approval of training coordinator of the department and with informed consent from the students. During routine medical undergraduate course, one lecture in anatomy covering 'human coronary circulation' was integrated with the physiology lecture of same topic. Anatomy lecture was followed by physiology lecture; each lecture being of 45 minutes duration.
Pre-test was conducted after anatomy lecture i.e. before the commencement of physiology lecture. It consisted of 10 multiple-choice questions (MCQs) covering the core areas of learning in anatomy of coronary circulation. MCQs consisted of both open and closed ended questions. Post-test was conducted at the end of physiology lecture and consisted of same 10 MCQs used in pretest. Each question of both pre-test and post-tests were awarded one mark each. Subjective assessment of the teaching method was done in the form of questionnaires with responses from the participating students. Relevant statistical tests were carried out to compare the performance of students in pre-test and post-test. Response to questionnaire was similarly evaluated.

\section{RESULTS}

Among a total of 118 students participating in the study, 23 were females and rest were males. The mean score in pre-test and post-test score revealed no statistically significant difference (table 1). In the subjective assessment $76 \%$ of students didn't have any past experience of integration of two different subjects. $87 \%$ students said that integration of anatomy and physiology lectures facilitated the understanding of the subject. $75 \%$ students wanted more topics to be taught in integrated manner in future whereas $23 \%$ students said that only few relevant topics should be integrated. The recommendation for the integration of more subjects was given by $47 \%$ students and the most chosen subject was

Table 1: Results of pre test and post test. Both tests comprised of 10 MCQs each.

\begin{tabular}{|l|c|c|c|}
\hline Test & Mean & SD & P value \\
\hline Pretest & 5.32 & 1.88 & 0.65 \\
\hline Posttest & 5.43 & 1.89 & \\
\hline
\end{tabular}


biochemistry. Most students said that such integration provided a better and holistic understanding of topics being covered. Students identified no disadvantages of integration. When asked for ways to improve the integration process they replied that there should be better coordination between instructors of two subjects, physiology should start from where anatomy leaves, some gap should be provided between lectures by taking lectures on two consecutive days and better time management should be exercised.

\section{DISCUSSION}

The objective result of the study showed no significant improvements in scores of post test from pre-test. On the other hand students subjectively responded positively to the integrated approach terming it superior to didactic lectures alone in providing better understanding. As Vernor 4 has suggested, integration did not differ from traditional methods on miscellaneous tests of factual knowledge.

Despite the interesting approaches taken at several institutions, the curriculum at most medical schools remains similar in form as advocated by Flexner ${ }^{5}$. Its principal features are a clear separation between basic and clinical sciences, basic sciences taught in the first year or two and the clinical subjects taught in the last two or three years. There is the use of didactic instruction in the form of lectures to large groups of students and an emphasis on the teacher's role as an expert source of information. Each department is relatively independent with poor coordination in teaching among them ${ }^{6}$.

Colliver found no convincing evidence that PBL improves knowledge base and clinical performance. At least not of the magnitude that would be expected given the resources required for a PBL curriculum ${ }^{7}$. In contrast Vernon and Blake in a meta-analysis found that PBL was significantly superior with respect to students' program evaluation. However, PBL and traditional methods did not differ on miscellaneous tests of factual knowledge ${ }^{4}$.

Harden et al. ${ }^{8}$ have identified six education strategies relating to the curriculum in a medical school as student-centred / teacher centred, problem-based / informationgathering, integrated / discipline-based, community-based / hospital-based, elective / uniform and systematic / apprenticeship-based (SPICES). This SPICES model of curriculum strategy analysis can be used in curriculum planning or review, in tackling problems relating to the curriculum and in providing guidance relating to teaching methods and assessment $^{8}$. Current system of didactic lectures alone is teacher centered whereas the integrated approach is a balanced one.

David hill ${ }^{9}$ has identified a system of medical teaching known by the acronym SCORPIO to address certain issues. Key elements of the system are that it is Structured, Clinical, Objective, Referenced, Problem-based, Integrated and Organized. SCORPIO involves delivering a syllabus through a series of lecture-demonstrations at which students, teachers and patients gather at a defined area ${ }^{9}$.

If the ultimate goal of medical education is to meet health needs of society, the primary goal of undergraduate medical education should be to produce students who are broadly skilled in the core competencies that transcend all disciplines of medicine ${ }^{10}$.

\section{CONCLUSION}

The integration of anatomy and physiology lectures in basic medical science education provides no extra advantage when it comes to retention of factual knowledge of anatomy. 
However, students feel that such integration provides them with holistic information than isolated lectures of traditional method.

\section{REFERENCES}

1. Older J. Anatomy: a must for teaching the next generation. The Surgeon. 2004;2(2): 79-90. http://dx.doi.org/10.1016/ s1479-666x(04)80050-7

2. Sugand K, Abrahams P, Khurana A. The anatomy of anatomy: A review for its modernization. Anatomical Sciences Education. 2010;3(2):83-93. http:// dx.doi.org/10.1002/ase.139

3. Harden RM, Davis MH, Crosby JR. The new Dundee medical curriculum: a whole that is greater than the sum of the parts. Medical education. 1997;31(4):264-71. http://dx.doi.org/10.1111/j. 1365-2923.1997.tb02923.x

4. Vernon DT, Blake RL. Does problem-based learning work? A meta-analysis of evaluative research. Academic medicine. 1993;68(7):550-63. http://dx.doi.org/ $\underline{10.1097 / 00001888-199307000-00015}$

5. Flexner A. Medical education in the United States and Canada bulletin number four (The Flexner Report). New York (NY): The Carnegie Foundation for the Advancement of Teaching. 1910.
6. Tosteson DC. New pathways in general medical education. New England Journal of Medicine. 1990;322(4):234-8. http:// dx.doi.org/10.1056/nejm199001253220405

7. Colliver JA. Effectiveness of problem-based learning curricula: research and theory. Academic Medicine. 2000;75(3):259-66. h t t p : / / d x. d o i . o r g / $\underline{10.1097 / 00001888-200003000-00017}$

8. Harden RM, Sowden S, Dunn WR. Educational strategies in curriculum development: the SPICES model. Medical Education. 1984;18(4):284-97. http:// d x . d o i.org/ $10.1111 / \mathrm{j}$. 1365-2923.1984.tb01024.x

9. Hill DA. SCORPIO: a system of medical teaching. Medical Teacher. 1992;14(1):

3 7-4 1. http://dx.doi.org/ $\underline{10.3109 / 01421599209044013}$

10. Hirsh DA, Ogur B, Thibault GE, Cox M. " Continuity" as an organizing principle for clinical education reform. New England Journal of Medicine. 2007;356(8):858. http://dx.doi.org/10.1056/nejmsb061660 